\title{
Dysregulated Handling of Dietary Protein and Muscle Protein Synthesis After Mixed-Meal Ingestion in Maintenance Hemodialysis Patients
}

\author{
Stephan van Vliet ${ }^{1}$, Sarah K. Skinner ${ }^{1}$, Joseph W. Beals ${ }^{2}$, Brandon A. Pagni ${ }^{1}$, Hsin-Yu Fang ${ }^{1}$, \\ Alexander V. Ulanov ${ }^{3}$, Zhong Li ${ }^{3}$, Scott A. Paluska ${ }^{4}$, Michael Mazzulla ${ }^{5}$, Daniel W.D. West ${ }^{5}$, \\ Daniel R. Moore ${ }^{5}$, Kenneth R. Wilund ${ }^{1,2}$ and Nicholas A. Burd ${ }^{1,2}$

\begin{abstract}
${ }^{1}$ Department of Kinesiology and Community Health, University of Illinois at Urbana-Champaign, Urbana, Illinois, USA; ${ }^{2}$ Division of Nutritional Sciences, University of Illinois at Urbana-Champaign, Urbana, Illinois, USA; ${ }^{3}$ Roy J. Carver Biotechnology Center, University of Illinois at Urbana-Champaign, Urbana, Illinois, USA; ${ }^{4}$ Department of Family Medicine, University of Illinois at Urbana-Champaign, Urbana, Illinois, USA; and ${ }^{5}$ Faculty of Kinesiology and Physical Education, University of Toronto, Toronto, Ontario, Canada
\end{abstract}

\begin{abstract}
Introduction: Skeletal muscle loss is common in patients with renal failure who receive maintenance hemodialysis (MHD) therapy. Regular ingestion of protein-rich meals are recommended to help offset muscle protein loss in MHD patients, but little is known about the anabolic potential of this strategy.
\end{abstract}

Methods: Eight MHD patients (age: $56 \pm 5$ years; body mass index [BMI]: $32 \pm 2 \mathrm{~kg} / \mathrm{m}^{2}$ ) and 8 nonuremic control subjects (age: $50 \pm 2$ years: BMl: $31 \pm 1 \mathrm{~kg} / \mathrm{m}^{2}$ ) received primed continuous L-[ring- $\left.{ }^{2} \mathrm{H}_{5}\right]$ phenylalanine and L-[1- $\left.{ }^{13} \mathrm{C}\right]$ leucine infusions with blood and muscle biopsy sampling on a nondialysis day. Participants consumed a mixed meal (546 kcal; $20-\mathrm{g}$ protein, $59-\mathrm{g}$ carbohydrates, $26-\mathrm{g}$ fat) with protein provided as $\mathrm{L}-\left[5,5,5-{ }^{2} \mathrm{H}_{3}\right]$ leucine-labeled eggs.

Results: Circulating dietary amino acid availability was reduced in MHD patients $(41 \pm 5 \%)$ versus control subjects (61 $\pm 4 \% ; P=0.03$ ). Basal muscle caspase-3 protein content was elevated $(P=0.03)$ and large neutral amino acid transporter 1 (LAT1) protein content was reduced $(P=0.02)$ in MHD patients versus control subjects. Basal muscle protein synthesis (MPS) was $\sim 2$-fold higher in MHD patients $(0.030 \pm$ $0.005 \% / \mathrm{h})$ versus control subjects $(0.014 \pm 0.003 \% / \mathrm{h})(P=0.01)$. Meal ingestion failed to increase MPS in MHD patients (absolute change from basal: $0.0003 \pm 0.007 \% / \mathrm{h}$ ), but stimulated MPS in control subjects $(0.009 \pm 0.002 \% / \mathrm{h} ; P=0.004)$.

Conclusions: MHD patients demonstrated muscle anabolic resistance to meal ingestion. This blunted postprandial MPS response in MHD patients might be related to high basal MPS, which results in a stimulatory ceiling effect and/or reduced plasma dietary amino acid availability after mixed-meal ingestion.

Kidney Int Rep (2018) 3, 1403-1415; https://doi.org/10.1016/j.ekir.2018.08.001

KEYWORDS: chronic kidney disease; inflammation; insulin resistance; nutrition; protein digestion

(C) 2018 International Society of Nephrology. Published by Elsevier Inc. This is an open access article under the CC BYNC-ND license (http://creativecommons.org/licenses/by-nc-nd/4.0/).

$\mathrm{P}$ atients with chronic renal failure who are undergoing MHD experience a number of metabolic and phenotypic derangements, including skeletal muscle wasting. ${ }^{1}$ MHD patients lose $\sim 1-$ to $3-\mathrm{kg}$ muscle mass annually, ${ }^{2}$ and this results in reduced functional capacity $^{3}$ and an increased risk for morbidity and

Correspondence: Nicholas A. Burd, Department of Kinesiology and Community Health, University of Illinois at UrbanaChampaign, 352 Louise Freer Hall, 906 S. Goodwin Avenue, Urbana, Illinois 61801, USA. E-mail: naburd@illinois.edu

Received 16 May 2018; revised 5 July 2018; accepted 6 August 2018; published online 17 August 2018 mortality. ${ }^{4}$ The underlying mechanisms of skeletal muscle wasting in MHD patients is not clear, but likely involves several factors, including chronic inflammation, reduced protein intake, metabolic acidosis, insulin resistance, hormonal abnormalities, increased substrate oxidation, and a loss of nutrients and/or amino acids during dialysis. ${ }^{5}$ Thus, identification of more effective preventative strategies to attenuate muscle mass loss are mandatory to improve the quality of life in individuals on MHD.

It was previously demonstrated that dialysis treatment leads to increased rates of forearm phenylalanine uptake with even greater rates of phenylalanine 
release. ${ }^{7,8}$ This resulted in the overall negative forearm phenylalanine balance. ${ }^{7}$ Hence, the dialysis procedure itself is catabolic and induces a catabolic carryover for several hours after dialysis, ${ }^{7}$ which may disturb skeletal muscle and whole body protein metabolism in MHD patients. Moreover, dialysis treatment results in $\sim 20 \%$ losses of circulating amino acids in the dialysate. ${ }^{9,10}$ Collectively, this creates the need to replace amino acids by protein ingestion during and/or after dialysis. It is promising that intradialytic protein feeding can mitigate some of the amino acid losses on the whole body $^{11,12}$ and forearm (indirect estimate of muscle) level. ${ }^{11}$ However, due to concerns regarding patient safety (e.g., increased risk of postprandial hypotension, choking, infection, and so on) and staff burden, ${ }^{13}$ meal consumption during dialysis is currently not part of standard care in dialysis clinics in the USA. ${ }^{14}$ Therefore, the ingestion of protein-rich meals in between dialysis treatments is necessary to counterbalance the dialysisinduced catabolism and achieve the current recommended protein intakes (set at $1.2 \mathrm{~g} / \mathrm{kg}$ body weight per day) for MHD patients to limit muscle protein losses. ${ }^{15}$ However, the effectiveness of protein-rich meal ingestion in augmenting postprandial whole body and muscle protein metabolic responses in MHD patients remains undefined.

Therefore, the purpose of this study was to compare basal and postprandial whole body leucine body kinetics, muscle anabolic-sensing mechanisms, markers of muscle proteolysis, and myofibrillar protein synthesis rates to mixed-meal ingestion in MHD patients on a nondialysis day, and to compare these outcomes with age- BMI-matched control subjects. We specifically produced intrinsically L- $\left[5,5,5-{ }^{2} \mathrm{H}_{3}\right]$ leucine-labeled eggs ${ }^{16}$ to combine with primed constant infusion methods of stable isotope amino acid tracers. We hypothesized that mixed-meal ingestion would result in impaired dietary protein digestion and absorption kinetics in MHD patients compared with the control group. ${ }^{17}$ Similar to other anabolic resistant populations, ${ }^{18-21}$ we further hypothesized that the phosphorylation of anabolic and nutrient sensing mechanisms (i.e., mammalian target of rapamycin complex 1 [mTORCl] signaling and muscle LAT1 protein content) and muscle protein synthesis (MPS) rates in response to feeding would be diminished in MHD patients compared with the control group.

\section{METHODS}

\section{Participants and Ethical Approval}

Eight MHD patients (mean \pm SEM: age: $56 \pm 5$ years; BMI: $32 \pm 2 \mathrm{~kg} / \mathrm{m}^{2}$ ) and 8 control subjects (mean \pm SEM: age: $50 \pm 2$ years; BMI: $31 \pm 1 \mathrm{~kg} / \mathrm{m}^{2}$ ) volunteered for this study. The participants were matched for age, sex, BMI, and insulin resistance as defined by the homeostasis model assessment of insulin resistance. Participant characteristics are presented in Table 1. MHD patients and control participants were deemed eligible based on responses to a routine medical screening questionnaire and routine blood panels (see details in the following). All participants were informed about the experimental procedures, the purpose of the study, and all potential risks before giving written consent. Participants had no history of participating in stable isotope amino acid tracer experiments. For MHD patients, we requested physician clearance from their nephrologist to further ensure it was safe for the patient to participate in this study. The study was approved by the Institutional Review Board at University of Illinois at Urbana-Champaign and conformed to standards for the use of human participants in research as outlined in the seventh revision of the Declaration of Helsinki.

Table 1. Participant characteristics

\begin{tabular}{|c|c|c|c|}
\hline Characteristics & $\begin{array}{l}\text { MHD patients } \\
\quad(n=8)\end{array}$ & $\begin{array}{l}\text { Control subjects } \\
\quad(n=8)\end{array}$ & $P$ value \\
\hline Dialysis period (yr) & $5 \pm 1$ & - & - \\
\hline Age (yr) & $56 \pm 5$ & $50 \pm 2$ & 0.23 \\
\hline Male sex & $6(75 \%)$ & $6(75 \%)$ & - \\
\hline Weight (kg) & $94 \pm 9$ & $94 \pm 4$ & 0.98 \\
\hline BMI $\left(\mathrm{kg} / \mathrm{m}^{2}\right)$ & $32 \pm 2$ & $31 \pm 1$ & 0.56 \\
\hline Fat (\%) & $31 \pm 3$ & $29 \pm 2$ & 0.75 \\
\hline Lean body mass (kg) & $61 \pm 5$ & $65 \pm 4$ & 0.58 \\
\hline Systolic BP (mm Hg) & $144 \pm 5^{a}$ & $129 \pm 4$ & 0.04 \\
\hline Diastolic BP (mm Hg) & $78 \pm 4$ & $83 \pm 6$ & 0.77 \\
\hline Statins & $4(50)$ & $0(0)$ & - \\
\hline \multicolumn{4}{|l|}{ Blood metabolites } \\
\hline Fasting glucose (mg/dl) & $95 \pm 11$ & $89 \pm 3$ & 0.57 \\
\hline HOMA-IR & $3.9 \pm 0.9$ & $4.0 \pm 0.6$ & 0.57 \\
\hline Blood urea nitrogen $(\mathrm{mg} / \mathrm{dl})$ & $32 \pm 3^{a}$ & $15 \pm 1$ & $<0.001$ \\
\hline Creatinine (mg/dl) & $7.4 \pm 0.9^{a}$ & $1.1 \pm 0.1$ & $<0.001$ \\
\hline eGFR $\left(\mathrm{ml} / \mathrm{min}\right.$ per $\left.1.73 \mathrm{~m}^{2}\right)$ & $9 \pm 1^{a}$ & $82 \pm 6$ & $<0.001$ \\
\hline Total $\mathrm{CO}_{2}(\mathrm{mEq} / \mathrm{l})$ & $23 \pm 2$ & $21 \pm 1$ & 0.40 \\
\hline C-reactive protein (mg/l) & $12 \pm 3^{a}$ & $2 \pm 1$ & $<0.01$ \\
\hline Cortisol $(\mu \mathrm{g} / \mathrm{dl})$ & $14 \pm 4$ & $13 \pm 1$ & 0.71 \\
\hline Albumin (g/dl) & $3.6 \pm 0.1^{a}$ & $3.9 \pm 0.1$ & 0.04 \\
\hline \multicolumn{4}{|l|}{ Co-morbidities } \\
\hline Hypertension & $8(100)$ & $2(25)$ & - \\
\hline Diabetes mellitus & $1(12.5)$ & $0(0)$ & - \\
\hline Obesity & $4(50)$ & $4(50)$ & - \\
\hline Secondary hyperparathyroidism & $8(100)$ & $0(0)$ & - \\
\hline Arthritis & $8(100)$ & $0(0)$ & - \\
\hline Neuropathy & $2(25)$ & $0(0)$ & - \\
\hline History of cardiovascular disease & $2(25)$ & $1(12.5)$ & - \\
\hline Hematological disease & $2(25)$ & $0(0)$ & - \\
\hline Gastroesophageal reflux disease & $1(12.5)$ & $0(0)$ & - \\
\hline Liver disease & $2(25)$ & $0(0)$ & - \\
\hline
\end{tabular}

$\mathrm{BMI}$, body mass index; $\mathrm{BP}$, blood pressure; $\mathrm{CO}_{2}$, carbon dioxide; eGFR, estimated glomerular filtration rate; HOMA-IR, homeostasis model assessment of insulin resistance.

Data are mean \pm SEMs or no. (\%).

${ }^{a}$ Significantly different between groups. 


\section{Screening Protocol}

Body weight and height were measured, as well as body composition, by dual-energy x-ray absorptiometry (Hologic QDR 4500A, Bedford, MA). Participants were instructed to refrain from vigorous physical activity for 3 days before each trial and to maintain their habitual dietary pattern. Furthermore, MHD patients were instructed to maintain daily medication as prescribed by their healthcare provider. A single exception was made for 1 diabetic MHD patient, who refrained from insulin injection during the infusion trial. The classes of medications of the MHD patients were as follows: phosphatase binders $(n=8)$, calcimimetics $(\mathrm{n}=8)$, angiotensin-converting enzyme inhibitors $(\mathrm{n}=6)$, nonsteroidal anti-inflammatory drugs $(\mathrm{n}=6), \beta$-blockers $(\mathrm{n}=4)$, calcium channel blockers $(\mathrm{n}=4)$, diuretics $(\mathrm{n}=4)$, statins $(\mathrm{n}=4)$, proton pump inhibitors $(\mathrm{n}=3)$, xanthine oxidase inhibitors (antigout) $(\mathrm{n}=3)$, opioids $(\mathrm{n}=3)$, vasodilators $(\mathrm{n}=2)$, P2Y12 (platelet) inhibitors $(\mathrm{n}=2)$, serotonin-reuptake inhibitors (antidepressants) $(\mathrm{n}=2)$, antihistamine $(\mathrm{n}=1)$, prokinetic $(\mathrm{n}=1)$, and immunosuppressant $(\mathrm{n}=1)$. The classes of medications of the control subjects were nonsteroidal anti-inflammatory drugs $(\mathrm{n}=2)$.

All participants consumed a standardized meal of the same composition (320 kcal; 22-g protein, 43-g carbohydrates, 7-g fat) the evening before the infusion trial and were instructed to remain fasted. A 2-day dietary recall was performed using dietary analysis software (Nutritionist Pro, version 2.1.13, Axxya Systems, Redmond, WA). Average 2-day protein intake tended to be lower in MHD patients $(0.9 \pm 0.14 \mathrm{~g} / \mathrm{kg}$ body weight per day) compared with control subjects (1.14 $\pm 0.05 \mathrm{~g} / \mathrm{kg}$ body weight per day) $(P=0.07)$ with no differences in other macronutrients (all $P>0.05$ ) (Supplementary Table S1).

\section{Infusion Protocol}

On the day of the infusion trial, participants reported to the laboratory at 7:00 AM after an overnight fast. MHD patients were studied approximately 24 hours after their previous dialysis treatment. A Teflon catheter was inserted into an antecubital vein for baseline blood sample collection $(t=-180$ minutes), after which participants received priming doses of labeled isotopic bicarbonate $(2.35 \mu \mathrm{mol} / \mathrm{kg}), \mathrm{L}-\left[1-{ }^{13} \mathrm{C}\right]$ leucine (7.6 $\mu \mathrm{mol} / \mathrm{kg}$ fat-free mass), and L-[ring- $\left.{ }^{2} \mathrm{H}_{5}\right]$ phenylalanine (2.0 $\mu \mathrm{mol} / \mathrm{kg}$ fat-free mass). Subsequently, a continuous i.v. infusion of $\mathrm{L}-\left[1-{ }^{13} \mathrm{C}\right]$ leucine $(0.10 \mu \mathrm{mol} / \mathrm{kg}$ fat-free mass per minute) and $\mathrm{L}$-[ring $\left.-{ }^{2} \mathrm{H}_{5}\right]$ phenylalanine (0.05 $\mu \mathrm{mol} / \mathrm{kg}$ fat-free mass per minute) was initiated $(t=-180$ minutes) and maintained until the end of the trial. A second Teflon catheter was inserted into a heated dorsal hand vein of the same arm for repeated arterialized blood sampling and remained patent by a $0.9 \%$ saline drip. In the postabsorptive state, muscle biopsies were collected at $t=-120$ and 0 minutes of the infusion. Biopsies were collected from the middle region of the vastus lateralis (15 cm above the patella) with a Bergström needle modified for suction under local anesthesia ( $2 \%$ lidocaine). The postabsorptive muscle biopsies were collected from the same incision with the needle pointed in the distal and proximal directions, respectively. Subsequently, participants consumed a mixed meal (see details in the following), and the completion of the meal marked the start of the postprandial phase ( $t=0$ minute). An additional muscle biopsy was collected at 300 minutes to determine musclerelated outcomes. The postprandial muscle biopsy was collected through a separate incision 2 to $3 \mathrm{~cm}$ above the postabsorptive incision. All biopsy samples were freed from any visible blood, adipose, and connective tissue, and immediately frozen in liquid nitrogen and stored at $-80^{\circ} \mathrm{C}$ until subsequent analysis.

Breath samples and arterialized blood samples were collected every 30 or 60 minutes during the postabsorptive and postprandial states. Total carbon dioxide production rates were measured with a metabolic cart (TrueOne 2400, ParvoMedics, Sandy, UT) at regular intervals throughout the infusion trials. The blood samples were immediately analyzed for whole blood glucose concentrations (2300 Stat Plus, YSI Life Sciences, Springs, $\mathrm{OH}$ ) and subsequently centrifuged at $3000 \mathrm{~g}$ for 10 minutes at $4{ }^{\circ} \mathrm{C}$. Aliquots of plasma were frozen and stored at $-80{ }^{\circ} \mathrm{C}$ until subsequent analysis. The breath samples were collected in $10-\mathrm{ml}$ vacutainers and stored at $20{ }^{\circ} \mathrm{C}$ until subsequent determination of carbon-13C dioxide enrichment by isotope ratio mass spectrometry (IDmicro Breath, Compact Science Systems Ltd, Newcastle-Under-Lyme, UK).

\section{Meal Composition}

Participants ingested a meal consisting of 3 scrambled $\mathrm{L}-\left[5,5,5-{ }^{2} \mathrm{H}_{3}\right]$ leucine-labeled eggs, 1 slice of toasted white bread, $300 \mathrm{ml}$ of apple juice, and $10 \mathrm{~g}$ of cow butter (546 kcal; 20-g protein, 59-g carbohydrates, 26-g fat). We chose this meal as a typical breakfast recommended for this patient population. ${ }^{22}$ The intrinsically $\mathrm{L}-\left[5,5,5-{ }^{2} \mathrm{H}_{3}\right]$ leucine-labeled eggs were specifically produced by supplementing the diet of laying hens (Lohmann LSL Whites) with $0.3 \% \mathrm{~L}-\left[5,5,5-{ }^{2} \mathrm{H}_{3}\right]$ leucine as described previously. ${ }^{16}$ The L- $\left[5,5,5-{ }^{2} \mathrm{H}_{3}\right]$ leucine enrichment of the eggs was determined by gas chromatography mass spectrometry (GC-MS) and averaged 13.1 mole percent excess (MPE). Proximate analyses for protein, lipid, and carbohydrate concentrations of the eggs were determined using the combustion method (method 990.03; 
AOAC International, 2000; TruMac; LECO Corp., Saint Joseph, MI). ${ }^{16}$ For the other foods, macronutrient composition was determined from their respective food labels. Leucine content of the whole eggs $(1.6 \mathrm{~g}$ for 3 eggs) were determined by GC-MS with integration of amino acid peak areas compared with an internal standard (DL-p-chlorophenylalanine) using the AMDIS software package (v. 2.71; NIST, Gaithersburg, MD). ${ }^{23}$

\section{Blood Analyses}

Blood metabolites were determined using a point-of-care chemistry analyzer (Piccolo Xpress Chemistry Analyzer; Abaxis, Union City, CA). Plasma insulin, cortisol, and high-sensitivity C-reactive protein concentrations were determined using a commercially available enzymelinked immunosorbent assays (Alpco Diagnostics; Salem, NH). Plasma amino acid concentrations and tracer enrichments were determined by GC-MS analysis (Agilent 7890A GC/5975C; MSD, Little Falls, DE) as described in our previous work. ${ }^{16}$ Briefly, plasma samples were prepared for amino acid analysis using a mixture of isopropanol/acetonitrile/water (3:3:2, v/v) and centrifuged at $20,000 \mathrm{~g}$ for 10 minutes at $4{ }^{\circ} \mathrm{C}$. Subsequently, the supernatant was dried and the amino acids converted into tert-butyldimethylsilyl ( $t$-BDMS) derivatives before GC-MS analysis. Plasma L- $\left[1-{ }^{13} \mathrm{C}\right]$ leucine and $\mathrm{L}-\left[5,5,5-{ }^{2} \mathrm{H}_{3}\right]$ leucine enrichments were determined by ion monitoring at mass/charge $(\mathrm{m} / \mathrm{z})$ ratios of $302(m+0), 303(m+1)$, and $305(m+3)$ with $m+0$ representing the lowest molecule weight of the ion, or unlabeled leucine. For L- $\left[\right.$ ring $\left._{-}{ }^{2} \mathrm{H}_{5}\right]$ phenylalanine, $m / z 336(m+0)$ and $341(m+5)$ were monitored for unlabeled and labeled phenylalanine, respectively. Plasma enrichments of the $t$-BDMS derivative of $\alpha_{-}\left[{ }^{13} \mathrm{C}\right]-$ ketoisocaproate were measured by GC-MS analysis by ion monitoring at $m / z$ ratios $232(m+0)$ and $233(m+1)$. The plasma leucine concentrations were determined by integrating amino acid peak areas in comparison to U$\left[{ }^{13} \mathrm{C}_{6}\right]$ leucine as an internal standard using the AMDIS software package (v. 2.71; NIST). ${ }^{23}$

\section{Muscle Analysis}

Myofibrillar protein-enriched fractions were isolated from $\sim 50 \mathrm{mg}$ of wet tissue and analyzed as described in our previous work. ${ }^{24}$ Briefly, myofibrillar-enriched protein pellets were hydrolyzed overnight in $6 \mathrm{M}$ hydrochloride at $110^{\circ} \mathrm{C}$. The resultant free amino acids were purified using cation exchange chromatography (Dowex 50W-X8-200 resin; Acros Organics, Geel, Belgium) and dried under vacuum. Free amino acids were resuspended in $60 \%$ methanol and centrifuged before the myofibrillar protein-bound enrichments were determined by 5500 QTRAP liquid chromatography-tandem mass spectrometry (Sciex, Framingham, MA). The myofibrillar protein-bound L-[ring- ${ }^{2} \mathrm{H}_{5}$ ]phenylalanine enrichments were determined by multiple reaction monitoring (MRM) at $\mathrm{m} / \mathrm{z} 166.0$ to 103.0 and 171.0 to 106.0 for unlabeled and labeled L-[ring- ${ }^{2} \mathrm{H}_{5}$ ]phenylalanine, respectively. Sciex Software Analyst 1.6.2 was used for data acquisition and analysis.

\section{Western Blotting}

A portion of whole muscle homogenates isolated during the myofibrillar protein extractions were used for examination of static snapshots of anabolic signaling mechanisms and proteolysis by Western blotting analysis as described in our previous work. ${ }^{24}$ The antibodies used to determine total protein content of mTOR at Ser2448 (cat. 2972), caspase-3 (cat. 9662S), and ubiquitin (cat. 3933) and phosphorylation of mTOR at Ser2448 (cat. 2971) were purchased from Cell Signaling Technology (Danvers, MA). Membranes from the respective proteins were incubated with appropriate secondary antibodies, and protein content was detected using West Femto Maximum Sensitivity substrate (SuperSignal, Thermo Scientific, Waltham, MA) and the ChemiDoc XRS+ Imaging System (Bio-rad, Hercules, CA). After detection of phosphorylation of mTOR at Ser2448, membranes were stripped with Western blot stripping buffer (Restore; Thermo Scientific) and reincubated with the antibody against total protein content of mTOR. Bands were quantified using ImageJ software (Protein Simple, San Jose, CA) and normalized to Ponceau S staining; this approach was validated as an alternative loading control (e.g., $\alpha$-actin) for Western blot analysis. ${ }^{25,26}$ In addition, data were standardized to a control sample included on each blot to account for interblot variability.

\section{Calculations}

Whole body leucine kinetics were assessed under nonsteady conditions by ingestion of $\mathrm{L}-\left[5,5,5-{ }^{2} \mathrm{H}_{3}\right]$ leucine eggs combined with i.v. infusion of $\mathrm{L}-\left[1-{ }^{13} \mathrm{C}\right]$ leucine. Total, exogenous (i.e., from dietary sources), and endogenous (i.e., breakdown) leucine rates of appearance and disappearance (i.e., synthesis) were calculated using modified Steele equations, ${ }^{27,28}$ as described in our previous work. ${ }^{24}$ Myofibrillar protein fractional synthesis rates (FSRs), a direct measurement of protein synthesis, were calculated using the standard precursor-product equation by dividing the increment in L- $\left[\right.$ ring- $\left.{ }^{2} \mathrm{H}_{5}\right]$-phenylalanine enrichment in the myofibrillar protein pool by the weighted average of L- $\left[\right.$ ring- $\left.{ }^{2} \mathrm{H}_{5}\right]$-phenylalanine enrichment in the plasma precursor pool over time.

\section{Statistics}

A power calculation based on previous research ${ }^{29}$ that assessed the feeding-mediated stimulation of myofibrillar 
protein synthesis rates showed that $\mathrm{n}=6$ was sufficient to detect differences between groups when using a 2-sided statistical test $(P<0.05,95 \%$ power, $f=0.86$; $\mathrm{G}^{*}$ power version 3.1.9.3). Considering a potential dropout rate of $20 \%$ during the protocol, the final number of participants recruited was 8 per group. Differences in participant characteristics, dietary intakes, within group FSRs, and net area under the time curves were analyzed by unpaired Student's $t$-test. Differences in time-dependent blood and muscle measurements were tested by 2 -factor (time $\times$ condition) repeated measures analysis of variance. When significant interaction effects were identified in the analysis of variance, Tukey post hoc tests were performed to determine the differences between means for all significant main effects and interactions. For all analysis, differences were considered significant at $P<0.05$. All calculations were performed using SPSS Statistics (version 24; IBM, Armonk, NY). All data are expressed as mean \pm SEMs.

\section{RESULTS}

\section{Plasma Metabolites}

Plasma leucine concentrations increased after meal consumption in both groups $(P<0.001)$ (Figure la). However, plasma leucine concentrations were lower in MHD patients compared with control subjects $(P=0.04)$. Plasma glucose concentrations increased after meal consumption $(P<0.001)$ to a greater extent in MHD patients compared with control subjects $(P=0.05)$ (Figure $1 \mathrm{~b})$. Plasma insulin concentrations increased after mixed-meal ingestion $(P<0.001)$ with no differences between groups $(P=0.29)$ (Figure 1c).

\section{Plasma Tracers and Whole Body Leucine Kinetics}

Plasma L- $\left[5,5,5-{ }^{2} \mathrm{H}_{3}\right]$ leucine enrichments increased to a greater extent between 90 and 180 minutes in the control group compared with the MHD patients $(P<$ 0.05) (Figure 2a). Plasma L- $\left[1-{ }^{13} \mathrm{C}\right]$ leucine enrichments decreased after meal ingestion $(P=0.02)$, with no differences between groups $(P=0.78)$ (Figure $2 b)$. Plasma $\alpha-\left[{ }^{13} \mathrm{C}\right]$ ketoisocaproate enrichments increased after meal ingestion $(P<0.001)$ to a greater extent in control subjects compared with MHD patients $(P=$ 0.04) (Figure 2c). Plasma L- $\left[\right.$ ring $\left._{-}{ }^{2} \mathrm{H}_{5}\right]$ phenylalanine enrichments decreased after mixed-meal ingestion $(P=$ 0.003), with no differences between groups $(P=0.71)$ (Figure 2d).

Exogenous leucine rates of appearance (representing the appearance of dietary protein-derived leucine into circulation) increased after mixed-meal consumption $(P<0.001)$. (Figure 3a). Exogenous leucine appearance rates were higher between 90 and 300 minutes after mixed-meal ingestion in the control subjects compared with MHD patients $(P<0.05)$. As such, the amount of dietary protein-derived leucine that appeared in circulation throughout the 0 - to 5-hour postprandial period was reduced in MHD patients $(41 \pm 5 \%)$ compared with control subjects $(61 \pm 4 \%)(P=0.03)$ (Figure 3b). Endogenous leucine rates of appearance (which represented the appearance of leucine derived from whole body protein breakdown into the circulation) decreased after meal consumption $(P<0.001)$, with no differences between groups $(P=0.41)$ (Figure 4a). Total leucine rates of appearance increased after meal consumption $(P=0.01)$, with no differences between groups $(P=0.94)$ (Figure $4 \mathrm{~b})$. Total leucine rates of disappearance tended to increase after meal consumption $(P=0.08)$, with no differences between MHD patients and control subjects $(P=0.86)$ (Figure 4c).

Area under the curves of fasted and fed rates of whole body protein breakdown, synthesis, oxidation, and net balance are presented in Figure 5. Whole body protein breakdown rates decreased after meal consumption $(P<0.001)$, with no differences between groups $(P=0.63)$. Whole body protein synthesis rates remained unchanged after meal consumption $(P=$ $0.33)$, with no differences between groups $(P=0.55)$. Whole body oxidation rates increased after meal consumption $(P=0.03)$, with no differences between MHD patients and control subjects $(P=0.12)$. However, whole body oxidation rates were lower overall in MHD patients compared with control subjects $(P=$ 0.04). Whole body net protein balance after mixedmeal consumption tended to increase to a greater extent in control subjects than that in MHD patients $(P=0.07)$.

\section{Muscle Anabolic Signaling and Amino Acid Transporters}

Skeletal muscle LAT1 protein content was reduced in MHD patients compared with control subjects $(P=$ 0.016) (Figure 6a). There was no change in muscle LAT1 protein content after mixed-meal ingestion in MHD patients or control subjects $(P=0.99)$. There were no differences in the relative content of total mTORCl protein between the MHD patients and the control group $(P=0.34)$. Moreover, mTORCl phosphorylation did not differ from baseline after mixedmeal ingestion in the MHD patients or the control group $(P=0.61)$ or between groups $(P=0.40)$ (Figure 6b). Representative blots are shown in Supplementary Figure S1.

\section{Muscle Proteolysis}

Relative muscle caspase- 3 protein content in the basal state was elevated in MHD patients compared with 

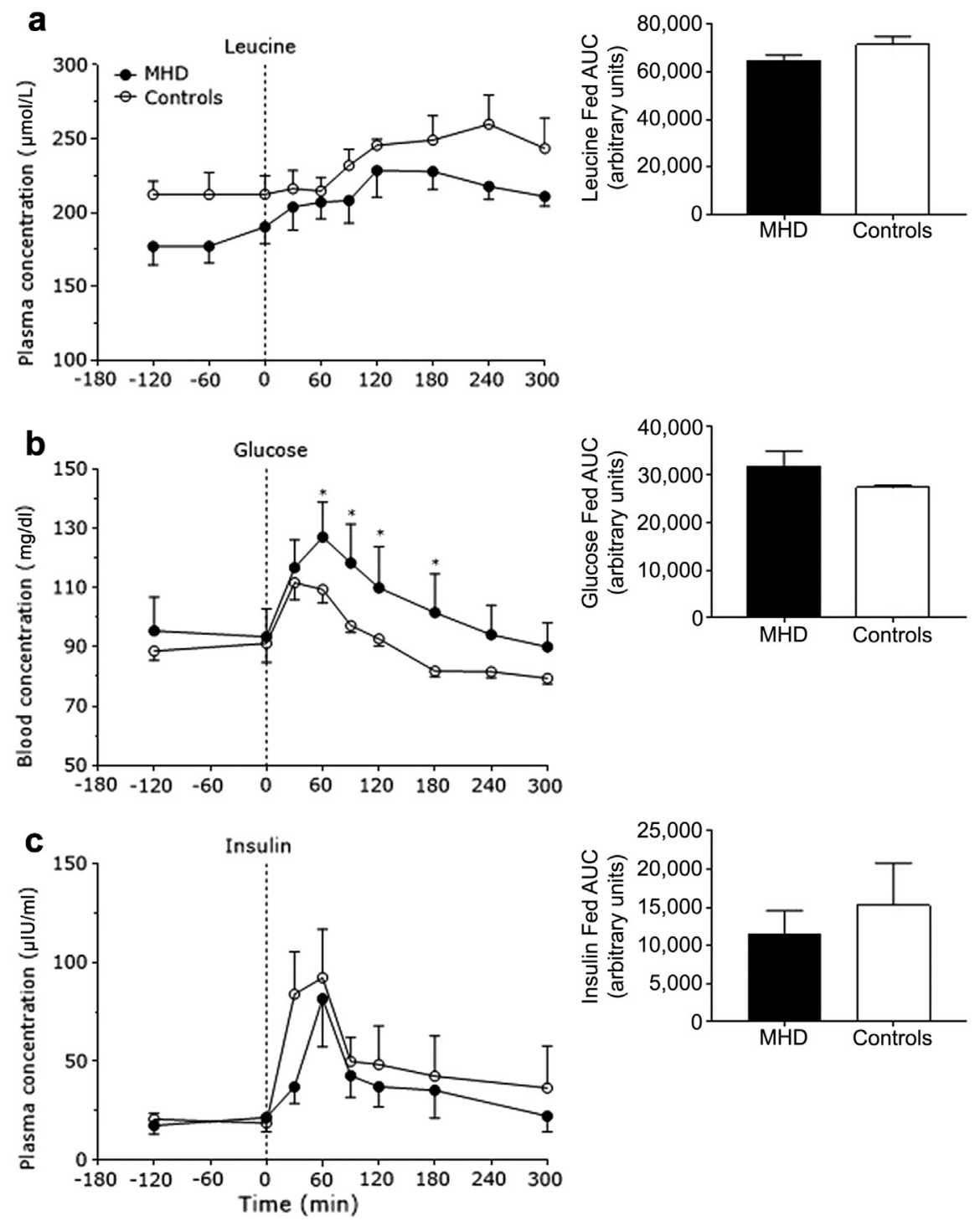

Figure 1. Plasma leucine (in micromoles per liter) (a), blood glucose (in milligram per deciliter) (b), and plasma insulin concentrations (in micro-International Units per milliliter) (c) in the basal state and after mixed-meal ingestion in maintenance hemodialysis (MHD) patients $(n=8)$ and control subjects $(n=8)$. Insets show the areas under the time curves $(A U C)$ for the fed state. Dashed lines refer to meal ingestion. Data are mean \pm SEMs. ${ }^{*}$ Significantly different compared with MHD at that time point. Insets: all $P>0.05$.

control subjects $(P=0.033)$. There was trend for muscle caspase-3 protein contents to be different in the fed state between MHD patients and control subjects $(P=0.08)$. Mixed-meal ingestion did not change muscle caspase-3 protein content in MHD patients or control subjects $(P=0.85)$ (Figure $7 b)$. Muscle ubiquitin protein content was not different between MHD patients and control subjects $(P=0.23)$ (Figure $7 \mathrm{c})$. Representative blots are shown in Supplementary Figure S2.

\section{Myofibrillar Protein Synthesis}

Basal rates of myofibrillar protein synthesis were $\sim 2$-fold higher in MHD patients compared with control subjects $(P=0.001)$ (Figure 8$)$. Meal ingestion did not increase myofibrillar protein synthesis rates in MHD patients (absolute change from basal: $0.0003 \pm$ $0.005 \% / \mathrm{h})$ or control subjects $(0.009 \pm 0.002 \% / \mathrm{h})(P=$ $0.20)$. There was a trend for the 0 - to 5 -hour postprandial myofibrillar protein synthetic to be greater in the MHD patients versus the control group $(P=0.07)$. Due to the strong main effect of MHD on FSRs within the 2-factor analysis of variance, we ran a paired $t$-test to assess and isolate the effectiveness of our feeding intervention to elicit an increase in postprandial myofibrillar protein synthesis rates in the control group. Using this approach, we observed an increase in postprandial myofibrillar protein synthesis above basal after mixed-meal ingestion in the control subjects 

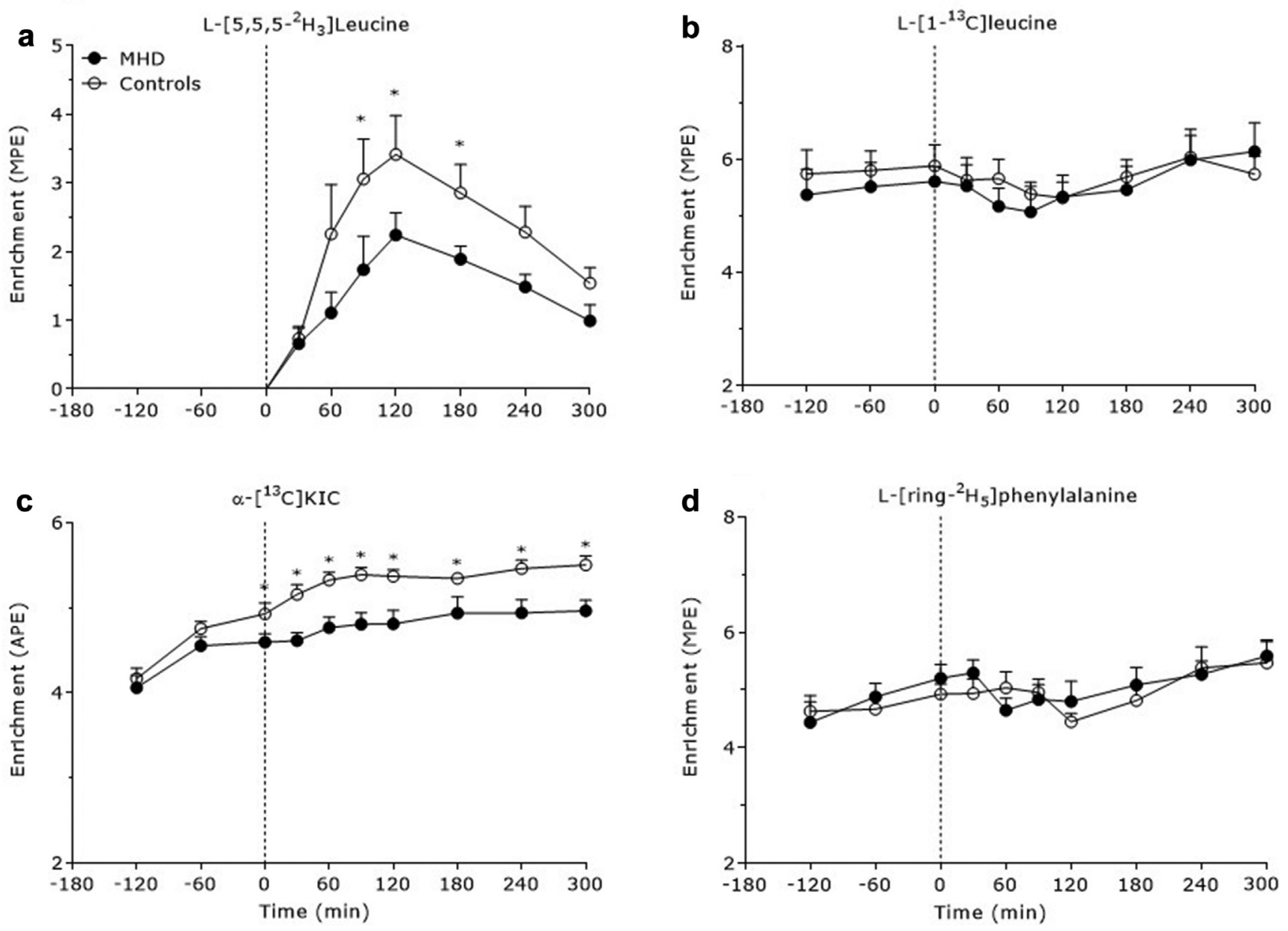

Figure 2. Plasma L- $\left[5,5,5-{ }^{2} \mathrm{H}_{3}\right]$ leucine (a), L- $\left[1-{ }^{13} \mathrm{C}\right]$ leucine (b), $\alpha-\left[{ }^{13} \mathrm{C}\right]$-ketoisocaproate (c), and L- $\left[\right.$ ring- $\left.{ }^{2} \mathrm{H}_{5}\right]$ phenylalanine (d) enrichments over time in the basal state and after meal consumption in maintenance hemodialysis (MHD) patients $(n=8)$ and control subjects ( $n=8)$. Dashed lines refer to meal ingestion. Data are expressed as mole percent excess (MPE) $(a, b, d)$ and atom percent excess (APE) (c). Data are mean \pm SEMs. * Significantly different compared with MHD at that time point.

$(t$-test: $P=0.004)$ but not in the MHD patients $(t$-test: $P=0.93)$.

\section{DISCUSSION}

The frequent ingestion of protein-rich meals is recommended to achieve higher daily protein intakes to offset net muscle protein loss in MHD patients. ${ }^{22}$ However, there are major gaps in our knowledge of how skeletal muscle mass is regulated by protein ingestion in MHD patients. This represents a significant challenge when attempting to design nutritional strategies to prevent muscle wasting in this patient group.
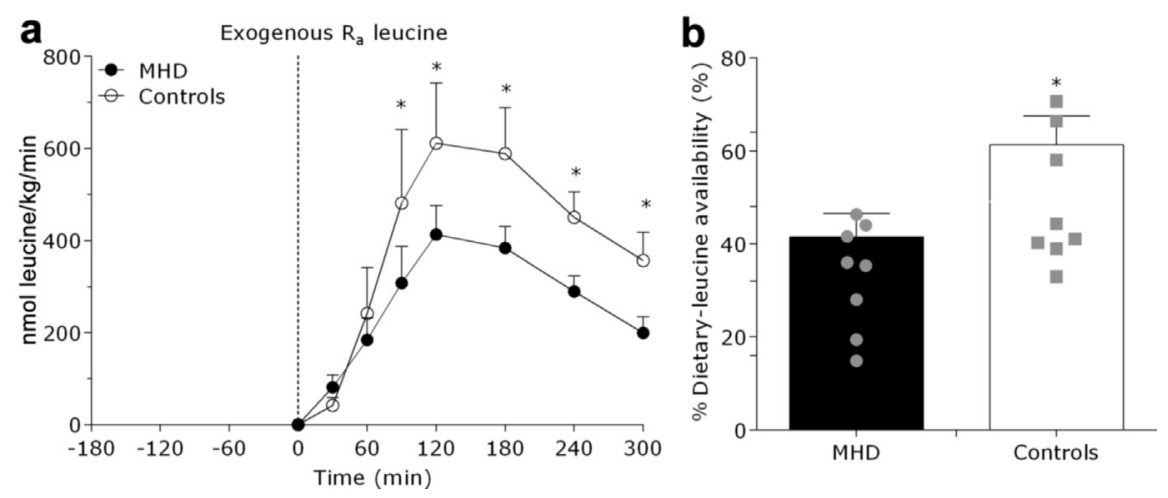

Figure 3. Exogenous leucine rate of appearance $\left(R_{a}\right)$, index of protein digestion and absorption kinetics (in nanomole leucine/kg per min) (a), and the amount of dietary protein-derived amino acids that appeared in circulation (percentage dietary leucine that appeared in the plasma after meal consumption) (b) after mixed-meal ingestion in maintenance hemodialysis (MHD) patients $(n=8)$ and control subjects $(n=8)$. Dashed line refers to mixedmeal ingestion. Gray shapes denote individual data in each group. Data are mean \pm SEMs. ${ }^{*}$ Significantly different compared with MHD at that time point. 

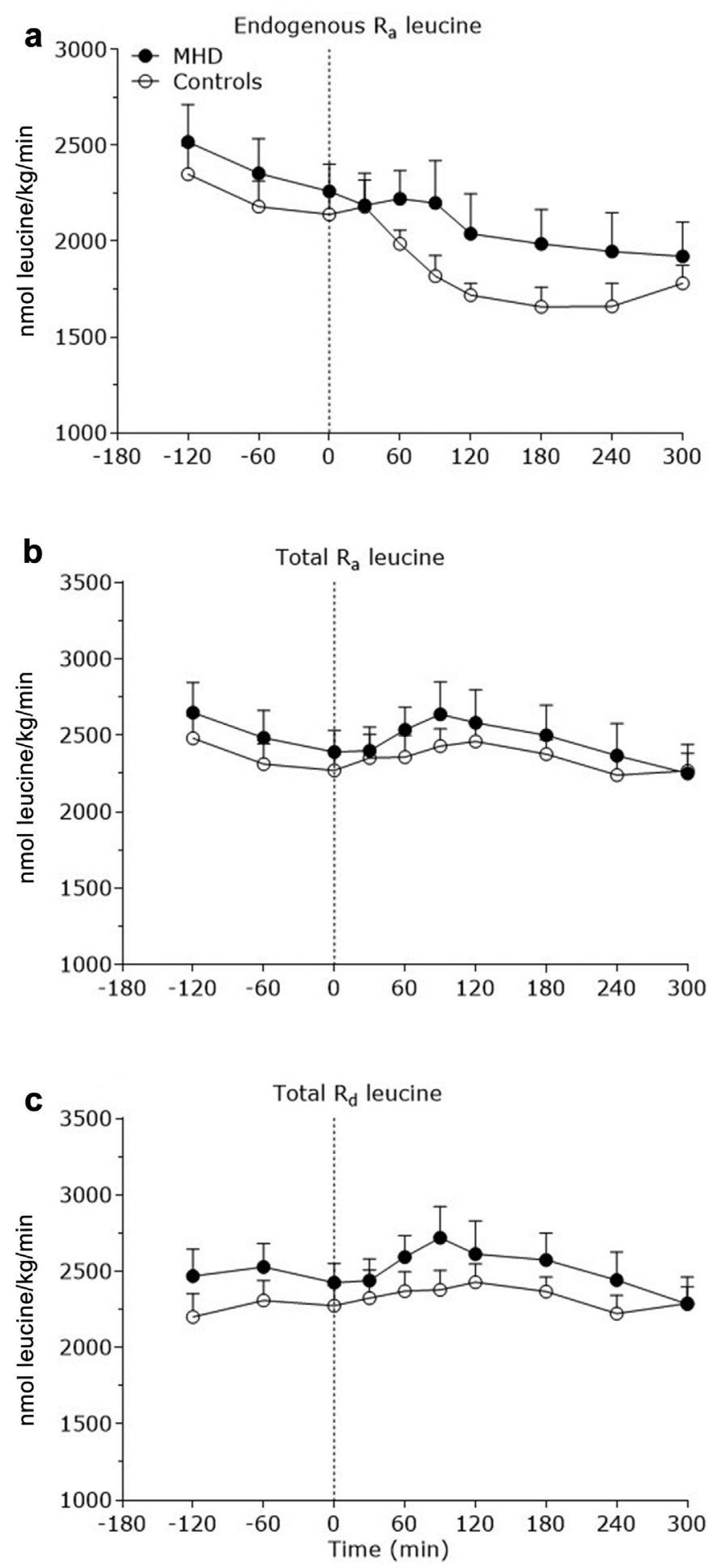

Figure 4. Endogenous leucine rate of appearance $\left(R_{a}\right)(a)$, total leucine $R_{a}(b)$, and total leucine $R_{d}(c)$ over time in the basal state and after meal consumption in maintenance hemodialysis (MHD) patients $(n=8)$ and control subjects $(n=8)$. Dashed lines refer to meal ingestion. Data are mean \pm SEMs.

We demonstrated that skeletal muscle subject to MHD is overstimulated in the basal state because myofibrillar protein synthesis rates are elevated $\sim 2$-fold (coupled with increased proteolysis) compared with age- and BMI-matched control subjects. Moreover, dietary
Whole-body metabolism

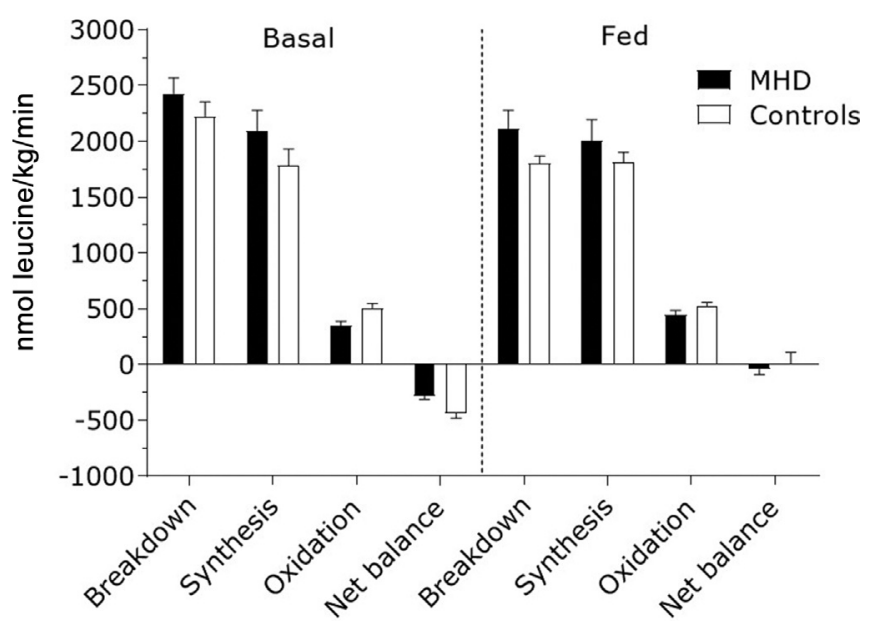

Figure 5. Whole-body leucine metabolism shown as the area under the curve of endogenous rate of appearance (marker of protein breakdown), nonoxidative leucine disposal (marker of protein synthesis), leucine oxidation (oxidation), and net leucine balance in the basal state and after meal consumption in maintenance hemodialysis (MHD) patients $(n=8)$ and control subjects $(n=8)$. Dashed line refers to meal ingestion. Data are mean \pm SEMs.

protein-derived amino acid availability in circulation and the postprandial myofibrillar protein synthetic response were impaired in individuals in MHD patients versus control subjects.

We chose to fractionate and target the synthetic rates of the myofibrillar fraction because this protein pool accounts for approximately $60 \%$ to $65 \%$ of all skeletal muscle proteins, represents the major force producing units in muscle, and is extremely sensitive to dietary amino acids in circulation in humans. ${ }^{30,31} \mathrm{We}$ demonstrated that basal myofibillar protein synthesis rates are elevated in MHD patients versus control subjects (Figure 8). It was shown that postabsorptive MPS rates are directly, and inversely, linked to the magnitude of stimulation of postprandial MPS rates after protein ingestion in other anabolic resistant populations (e.g., the aging). ${ }^{21}$ In our work, basal-state myofibrillar protein synthesis rates in MHD patients were likely nearing a stimulatory ceiling or an upper physiological limit, and this might explain the inability of dietary amino acids in circulation to signal a robust rise in the postprandial muscle protein synthetic response in MHD patients compared with control subjects. Previous work showed that the intradialytic period is characterized by increased mixed MPS rates ${ }^{32}$ and results in net efflux of amino acids from skeletal muscle. ${ }^{7,8}$ The efflux of amino acids from proteolysis is likely the result of increased demand for amino acids by visceral organs (particularly, the splanchnic region) during hemodialysis. ${ }^{33}$ Our work could indicate a 

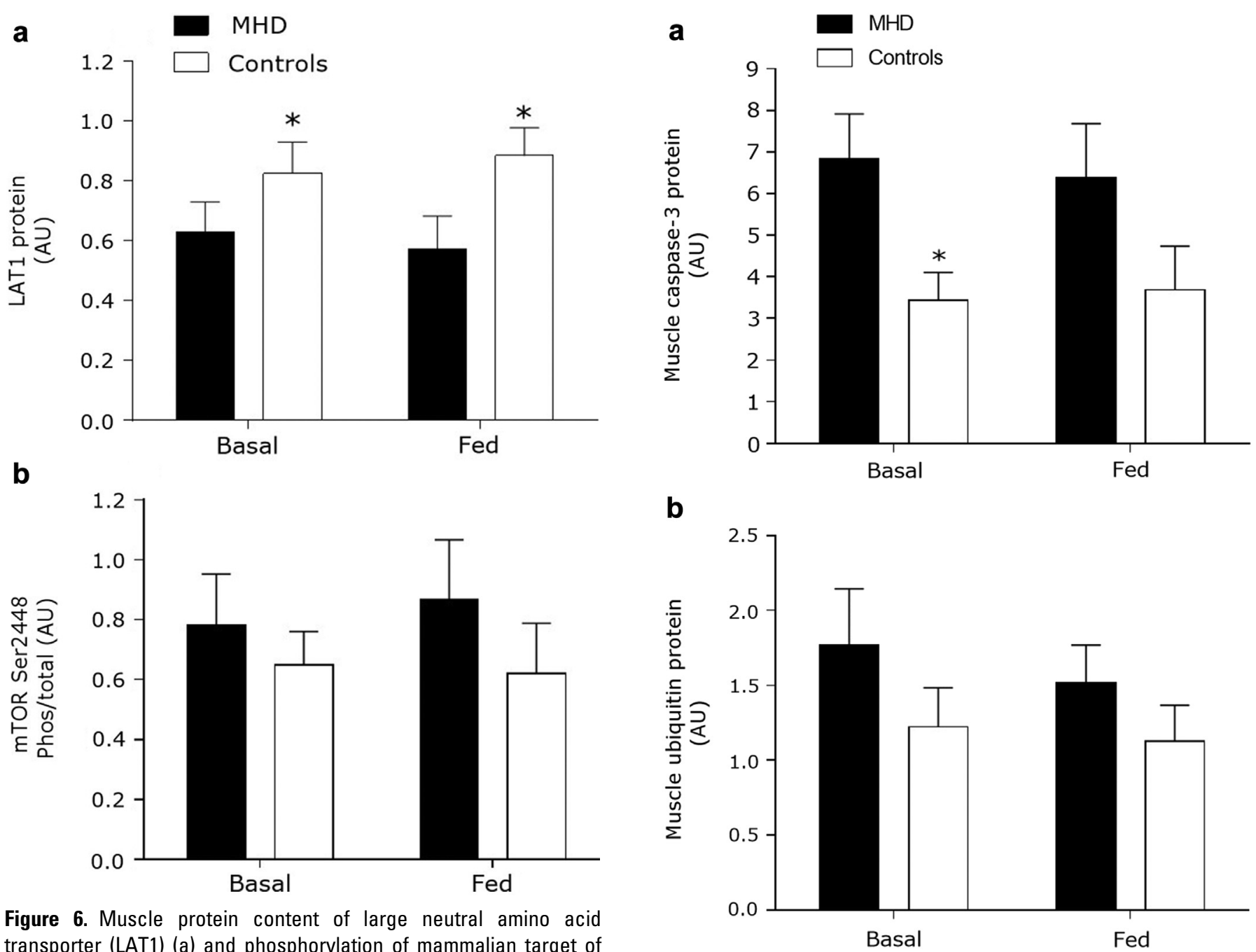

Figure 6. Muscle protein content of large neutral amino acid transporter (LAT1) (a) and phosphorylation of mammalian target of rapamycin complex 1 (mTORC1) at Ser2448 (b) before and after mixed-meal ingestion in maintenance hemodialysis (MHD) patients $(n=8)$ and control subjects $(n=8)$. Data are mean \pm SEMs. AU, arbitrary units. ${ }^{*}$ Significantly different compared with MHD at that time point.

catabolic carryover from hemodialysis into nontreatment days, and thus might contribute to the observed dysregulated muscle protein metabolic responses in MHD patients. Importantly, this interorgan amino acid exchange is generally masked on a whole body level, and similar to others, ${ }^{7,8}$ we observed marked disturbances in muscle protein kinetics with no apparent differences in whole body protein breakdown, synthesis, or net balance (Figure 5).

In this study, we did not directly measure muscle protein breakdown rates, and instead relied on static markers of muscle proteolysis. This was due to the fact that the modeling of muscle fractional protein breakdown rates is problematic without a physiological steady-state, and there is no method to measure fractional protein breakdown rates within specific muscle protein fractions (i.e., myofibillar protein pool). However, examination of static snapshots of proteolysis

Figure 7. Muscle protein content for caspase-3 (a) and ubiquitin (b) before and after mixed-meal ingestion in maintenance hemodialysis (MHD) patients $(n=8)$ and control subjects $(n=8)$. Data are mean \pm SEMs. AU, arbitrary units. *Significantly different compared with MHD at that time point.

revealed that the relative protein content of caspase- 3 is elevated in MHD patients compared with control subjects (Figure 7). Moreover, MPS and breakdown rates were shown to be interconnected in healthy adults ${ }^{34}$ and in MHD patients. ${ }^{32}$ Thus, we interpreted our findings of elevated basal myofibrillar protein synthesis rates and increased muscle caspase- 3 protein content in MHD patients as evidence of persistent hypercatabolism, which could be the result of a variety of end-stage renal disease-related factors, such as a direct catabolic carryover effect of the dialysis procedure itself, ${ }^{7,8}$ several comorbidities (including chronic systemic inflammation), secondary hyperparathyroidism, ${ }^{36}$ and/or medication use (e.g., statins).

To offset the hemodialysis-induced catabolic state, the ingestion of protein-rich meals in between dialysis treatments is recommended as the main strategy to limit muscle protein losses. ${ }^{15}$ We demonstrated an anabolic 

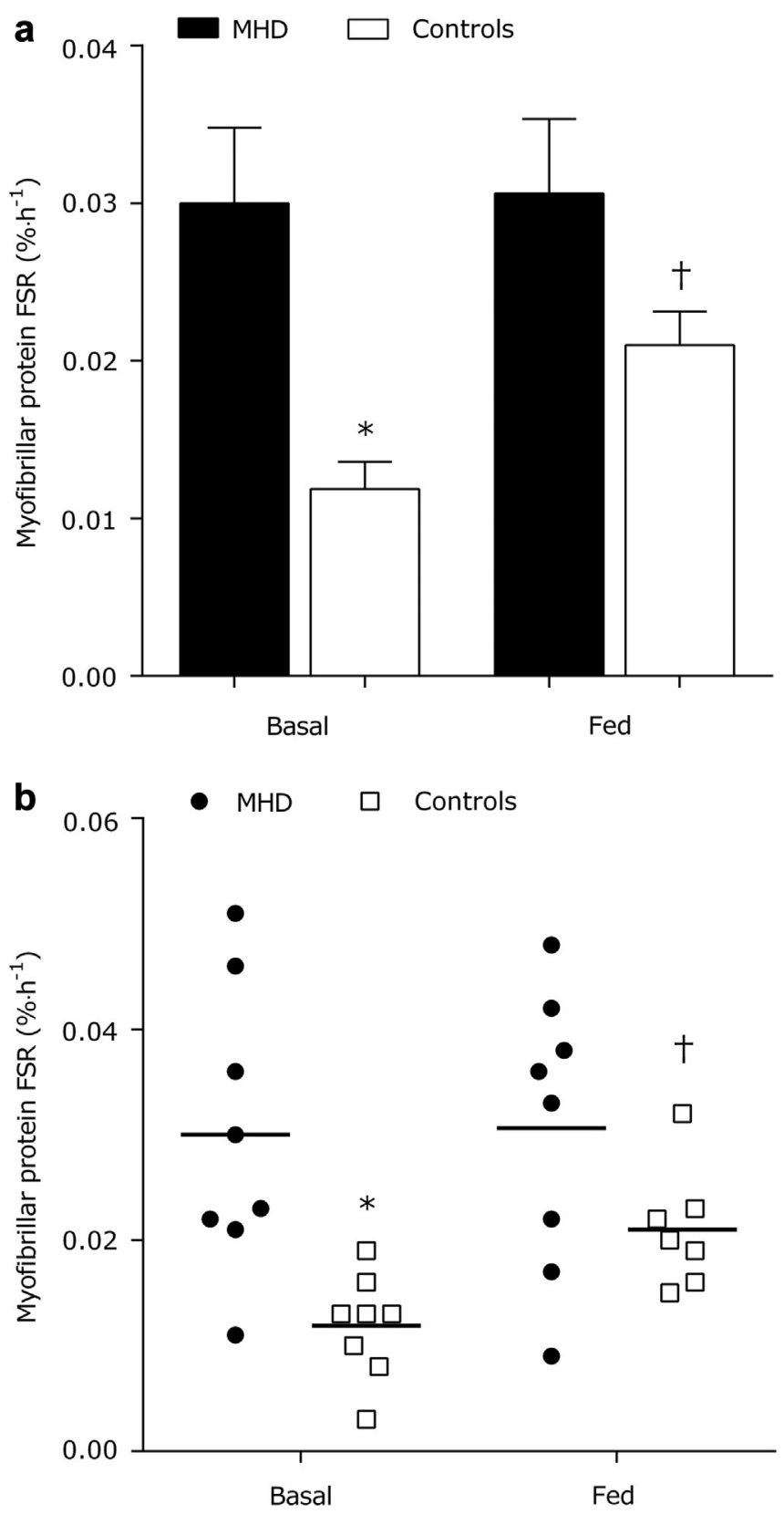

Figure 8. Myofibrillar protein synthesis (a) expressed as the fractional synthesis rate (FSR) before (basal) and after mixed meal ingestion in MHD patients $(n=8)$ and control subjects $(n=8)$. Individual data for the myofibrillar protein synthesis responses in MHD patients and control subjects (b). *Significantly different compared with MHD at that time point. Note different scales on y-axes between graphs. TSignificantly different from basal.

resistance of myofibrillar protein synthesis rates after the ingestion of a typical recommended breakfast (containing $20 \mathrm{~g}$ protein and $546 \mathrm{kcal}$ ) for this patient population. ${ }^{22}$ The postprandial protein-derived amino acid availability in circulation after the ingestion of a meal is an important determinant of MPS rates. ${ }^{38,39}$ We demonstrated that the postprandial release of dietary amino acids into the circulation was reduced in MHD patients compared with control subjects. As a result, the total amount of protein-derived amino acid availability in circulation was lower in MHD patents (41 $\pm 5 \%$ ) compared with control subjects $(61 \pm 4 \%)$ throughout the postprandial period. This notion was further supported by peak plasma leucine concentrations that were approximately $14 \%$ lower in the MHD patients, with no differences in total whole body amino acid flux rates or plasma distribution volumes for leucine, compared with control subjects. This implied that impairments in protein digestion, amino acid absorption, and/or increased splanchnic sequestration of amino acids were other potential factors that might provide an explanation for why feeding failed to elicit a postprandial rise in myofibrilllar protein synthesis rates in these patients. However, MHDrelated increases in splanchnic sequestration (namely, in the gut and liver) of amino acids might be the most prevalent site of dysregulation. MHD patients are commonly characterized by several splanchnic abnormalities, such as intestinal small bacterial overgrowth, ${ }^{40}$ gut microbiome alterations, ${ }^{41}$ gastrointestinal inflammation, ${ }^{42}$ gut motility disorders, ${ }^{43}$ hypergastrinemia, ${ }^{44}$ and increased hepatic protein synthesis rates. ${ }^{8}$ All these MHD-related factors have the potential to contribute to the lower postprandial protein-derived amino acid availability in circulation after eating a proteincontaining meal. Moreover, similar observations of increased first-pass splanchnic extraction of dietary amino acids (leucine) were shown with aging, ${ }^{45}$ and this population also demonstrated chronic low-grade inflammation. The potential mechanisms underpinning the agerelated increase in splanchnic sequestration of amino acids was suggested as being related to increased gut and/ or liver protein synthesis, increased amino acid extraction by resident macrophages in the liver, or altered leucine aminotransferase activity in splanchnic tissues. ${ }^{46}$ Similar mechanisms might be in play in MHD patients, but more work is required to confirm any of the preceding speculations.

We measured relevant nutrient-sensing and anabolicsignaling mechanisms in muscle to probe other factors that might underpin the anabolic resistance in patients on MHD. We showed that both basal and fed-state muscle LATl protein content was reduced in MHD patients compared with control subjects. LATl is an amino acid transporter that is found in close proximity to capillaries ${ }^{47}$; it imports leucine and other amino acids into muscle cells via glutamine exchange. ${ }^{47,48}$ Previously, it was demonstrated that MHD patients have higher muscle and/or plasma gradients compared with control subjects, ${ }^{49}$ which might indicate a failure to effectively export glutamine from muscle cells, which in turn, interferes with effective leucine import into muscle cells. Alternatively, the lower skeletal muscle LAT1 protein content in MHD patients could simply be related to the lower plasma leucine concentrations in 
this patient population. Thus, it remains to be established if an MHD-related reduction in muscle LAT1 protein content represents a relevant site of impairment. Moreover, fed-state mTORCl phosphorylation did not differ between the MHD patients and control subjects (Figure 6). The lack of observed effect of mTORCl phosphorylation between MHD patients and control subjects might be related to the timing of the postprandial muscle biopsies, which was designed for the FSR measurement, as opposed to capturing optimal anabolic-signaling mechanisms. ${ }^{50}$ Specifically, mTORC1 phosphorylation is more robust early ( $1-2$ hours) after a feeding stimulus. ${ }^{50}$ Moreover, total protein content via Western blot did not provide insight into the intracellular localization of these transporters nor did their activity level and/or transport capacity. Thus, it is unclear if the lower LAT1 protein content in MHD might have contributed to the lack of postprandial myofibrillar protein synthetic response via an attenuated uptake of dietary amino acids. Raj et al. ${ }^{32}$ reported that the dialysis procedure did not affect leucine inward transport into MHD muscles, although without a control group, it was not possible to isolate if problems existed in amino acid transport capacity in this patient population. Thus, additional research is warranted to elucidate the mechanism(s) by which MHD skeletal muscle becomes anabolically resistant to dietary amino acids in circulation.

From a methodical perspective, our experimental design of combining the ingestion of intrinsically $\mathrm{L}-\left[5,5,5-{ }^{2} \mathrm{H}_{3}\right]$ leucine-labeled eggs with primed constant infusions of L- $\left[1-{ }^{13} \mathrm{C}\right]$ leucine and L- $\left[\right.$ ring- $\left.^{2} \mathrm{H}_{5}\right]$ phenylalanine allowed us to calculate the release of dietary protein-derived amino acids into circulation and the subsequent postprandial myofibrillar protein synthetic response in MHD patients and control subjects. Specifically, the i.v. infusion of L- $\left[1-{ }^{13} \mathrm{C}\right]$ leucine was used to determine total leucine flux and leucine oxidation rates. The orally ingested $\mathrm{L}-\left[5,5,5-{ }^{2} \mathrm{H}_{3}\right]$ leucine allowed us to determine the rate of dietary protein-derived leucine into circulation (exogenous appearance rates) by repeated measurements of plasma leucine concentrations and enrichments throughout the postprandial period. As such, this methodology did not assess the true rate of dietary protein-derived amino acid absorption, and our findings were restricted to the assessed 5-hour postprandial period. Hence, our methodology did not allow us to determine if the impaired postprandial release of dietary amino acids into circulation in MHD patients was due to (i) incomplete digestion of dietary protein; (ii) increased splanchnic (i.e., gut and liver) amino acid uptake; or (iii) continued release of dietary protein-derived amino acids into the circulation after the measured 5-hour postprandial phase. In addition, the measurement of the increment of the myofibrillar protein bound L- $\left[\right.$ ring- $\left.^{2} \mathrm{H}_{5}\right]$ phenylalanine enrichment allowed us to calculate myofibrillar protein fractional synthetic rates, which is the most direct measurement of MPS (contractile) rates. Human MPS rates were shown to be influenced by a number of factors, such as age, ${ }^{21}$ obesity, ${ }^{29}$ insulin resistance, ${ }^{51}$ metabolic acidosis, ${ }^{52}$ and habitual physical activity level. ${ }^{34}$ To rule out the influence of several nonuremic factors on MPS, we intentionally recruited sedentary control subjects who were matched for age, sex, and the presence of obesity and insulin resistance. In addition, the MHD patients recruited for this study had metabolic acidosis corrected through routine bicarbonate supplementation. To confirm the absence of metabolic acidosis in MHD patients, plasma total carbon dioxide, which is a widely accepted clinical measurement of blood acid balance, ${ }^{53}$ revealed normal values in both the MHD patients $(23 \pm 2 \mathrm{mEq} / \mathrm{l})$ and control subjects $(21 \pm 1 \mathrm{mEq} / \mathrm{l})(P=0.40)$ (Table 1$)$. Thus, there is a clear defect in basal and postprandial myofibrillar protein synthesis rates in adults who receive MHD that cannot be explained by these extrinsic factors.

In conclusion, our data provided the first mechanistic basis into how dietary protein is handled in response to mixed-meal ingestion in MHD patients. We demonstrated that MPS rates in MHD patients are overstimulated in the basal state and muscle anabolic resistance to mixed-meal ingestion compared with ageand BMI-matched control subjects. This suggested that merely feeding a high protein meal is not a sufficient strategy to prevent muscle wasting in MHD patients. Studies are needed to identify if reducing the inflammatory and/or uremic milieu can restore the anabolic potential of feeding in MHD patients.

\section{DISCLOSURE}

All the authors declared no competing interests.

\section{ACKNOWLEDGMENTS}

The authors are grateful to the participants who volunteered for this study. They also thank the ChampaignUrbana Dialysis Center for allowing them to recruit in their clinic. Furthermore, they thank Carl. M. Parsons, Pamela L. Utterback, Christina D. Hanna, and the Department of Animal Sciences for their support in producing the intrinsically-labeled eggs.

Funding for this research was provided by a grant from the American Egg Board/Egg Nutrition Center. SvV was supported by a European Society for Clinical Nutrition and Metabolism Research Fellowship. Clinical Trial Registration Number: NCT03478722 (www.clinicaltrials.gov).

\section{AUTHOR CONTRIBUTIONS}

SvV and NAB designed the study. All authors carried out experiments. SvV, SKS, JWB, MM, DWDW, AVU, ZL, DRM, 
and $N A B$ analyzed the data. SvV and NAB made the figures. SvV and NAB drafted and revised the paper, and all authors approved the final version of the manuscript. Pubmed indexing was done by SvV, SKS, JWB, BAP, HYF, AVU, ZL, SAP, MM, DWDW, DRM, KRW, and NAB.

\section{SUPPLEMENTARY MATERIAL}

Figure S1. Representative blots of total protein content of large neutral amino acid transporter 1 (LAT1), phosphorylation and total protein content of mammalian target of rapamycin complex 1 (mTORC1) at Ser2448 before and after mixed meal ingestion in maintenance hemodialysis (MHD) patients $(n=8)$ and control subjects ( $\mathrm{n}=8$ ).

Figure S2. Representative blots of total protein content of caspase-3 and ubiquitin before and after mixed-meal ingestion in maintenance hemodialysis (MHD) patients ( $n=8$ ) and control subjects $(n=8)$.

Table S1. Self-reported dietary intake during 2 days before the infusion trial.

Supplementary material is linked to the online version of the paper at www.kireports.org.

\section{REFERENCES}

1. Workeneh BT, Mitch WE. Review of muscle wasting associated with chronic kidney disease. Am J Clin Nutr. 2010;91: 1128S-1132S.

2. Pupim LB, Heimburger O, Qureshi AR, et al. Accelerated lean body mass loss in incident chronic dialysis patients with diabetes mellitus. Kidney Int. 68:2368-2374.

3. Johansen $\mathrm{KL}$, Shubert T, Doyle J, et al. Muscle atrophy in patients receiving hemodialysis: effects on muscle strength, muscle quality, and physical function. Kidney Int. 2003;63: 291-297.

4. Hayhurst WSG, Ahmed A. Assessment of physical activity in patients with chronic kidney disease and renal replacement therapy. SpringerPlus. 2015;4:536.

5. Wang XH, Mitch WE. Mechanisms of muscle wasting in chronic kidney disease. Nature Rev Nephrol. 2014;10:504-516.

6. Stenvinkel P, Carrero JJ, von Walden F, et al. Muscle wasting in end-stage renal disease promulgates premature death: established, emerging and potential novel treatment strategies. Nephrol Dial Transplant. 2015;31:1070-1077.

7. Ikizler TA, Pupim LB, Brouillette JR, et al. Hemodialysis stimulates muscle and whole body protein loss and alters substrate oxidation. Am J Physiol Endocrinol Metab. 2002;282:E107-E116.

8. Raj DS, Dominic EA, Wolfe R, et al. Coordinated increase in albumin, fibrinogen, and muscle protein synthesis during hemodialysis: role of cytokines. Am J Physiol Endocrinol Metab. 2004;286:E658-E664.

9. Gil H-W, Yang J-O, Lee E-Y, et al. The effect of dialysis membrane flux on amino acid loss in hemodialysis patients. J Korean Med Sci. 2007;22:598-603.

10. Ikizler TA, Flakoll PJ, Parker RA, et al. Amino acid and albumin losses during hemodialysis. Kidney Int. 1994;46:830-837.
11. Pupim LB, Flakoll PJ, Brouillette JR, et al. Intradialytic parenteral nutrition improves protein and energy homeostasis in chronic hemodialysis patients. J Clin Invest. 2002;110: 483-492.

12. Veeneman JM, Kingma HA, Boer TS, et al. Protein intake during hemodialysis maintains a positive whole body protein balance in chronic hemodialysis patients. Am J Physiol Endocrinol Metab. 2003;284:E954-E965.

13. Kistler B, Benner D, Burgess M, et al. To eat or not to eatinternational experiences with eating during hemodialysis treatment. J Renal Nutr. 24:349-352.

14. Kalantar-Zadeh K, Alp Ikizler T. Let them eat during dialysis: an overlooked opportunity to improve outcomes in maintenance hemodialysis patients. J Renal Nutr. 2013;23:157163.

15. Clinical practice guidelines for nutrition in chronic renal failure. K/DOQI, National Kidney Foundation. Am J Kidney Dis. 2000;35:S1-S140.

16. van Vliet S, Beals JW, Parel JT, et al. Development of intrinsically labeled eggs and poultry meat for use in human metabolic research. J Nutr. 2016;146:1428-1433.

17. Bammens B, Verbeke K, Vanrenterghem Y, et al. Evidence for impaired assimilation of protein in chronic renal failure. Kidney Int. 2003;64:2196-2203.

18. Horstman AM, Sheffield-Moore M. Nutritional/metabolic response in older cancer patients. Nutrition. 2015;31:605-607.

19. Porter C, Cotter M, Diaz EC, et al. Amino acid infusion fails to stimulate skeletal muscle protein synthesis up to 1 year after injury in children with severe burns. J Trauma Acute Care Surg. 2013;74:1480-1485.

20. Williams JP, Phillips BE, Smith K, et al. Effect of tumor burden and subsequent surgical resection on skeletal muscle mass and protein turnover in colorectal cancer patients. Am J Clin Nutr. 2012;96:1064-1070.

21. Wall BT, Gorissen SH, Pennings B, et al. Aging is accompanied by a blunted muscle protein synthetic response to protein ingestion. PloS One. 2015;10:e0140903.

22. National Kidney Foundation. Dietary guidelines for adults starting on hemodialysis. Available at: https://www.kidney. org/atoz/content/dietary_hemodialysis. Accessed May 1, 2018.

23. Jimenez-Martin E, Ruiz J, Perez-Palacios T, et al. Gas chromatography-mass spectrometry method for the determination of free amino acids as their dimethyl-tert-butylsilyl (TBDMS) derivatives in animal source food. J Agricult Food Chem. 2012;60:2456-2463.

24. van Vliet S, Shy EL, Abou Sawan S, et al. Consumption of whole eggs promotes greater stimulation of postexercise muscle protein synthesis than consumption of isonitrogenous amounts of egg whites in young men. Am J Clin Nutr. 2017;106:1401-1412.

25. Rivero-Gutiérrez B, Anzola A, Martínez-Augustin O, et al. Stain-free detection as loading control alternative to Ponceau and housekeeping protein immunodetection in Western blotting. Anal Biochem. 2014;467:1-3.

26. Romero-Calvo I, Ocón B, Martínez-Moya P, et al. Reversible Ponceau staining as a loading control alternative to actin in Western blots. Anal Biochem. 2010;401:318-320. 
27. Boirie $Y$, Gachon P, Corny S, et al. Acute postprandial changes in leucine metabolism as assessed with an intrinsically labeled milk protein. Am J Physiol. 1996;271:E1083E1091.

28. Dangin M, Guillet C, Garcia-Rodenas C, et al. The rate of protein digestion affects protein gain differently during aging in humans. J Physiol. 2003;549:635-644.

29. Beals JW, Sukiennik RA, Nallabelli J, et al. Anabolic sensitivity of postprandial muscle protein synthesis to the ingestion of a protein-dense food is reduced in overweight and obese young adults. Am J Clin Nutr. 2016;104:10141022.

30. Moore DR, Tang JE, Burd NA, et al. Differential stimulation of myofibrillar and sarcoplasmic protein synthesis with protein ingestion at rest and after resistance exercise. J Physiol. 2009;587:897-904.

31. Cuthbertson D, Smith K, Babraj J, et al. Anabolic signaling deficits underlie amino acid resistance of wasting, aging muscle. FASEB J. 2005;19:422-424.

32. Raj DS, Zager P, Shah VO, et al. Protein turnover and amino acid transport kinetics in end-stage renal disease. Am J Physiol Endocrinol Metab. 2004;286:E136-E143.

33. Ferrando AA, Raj D, Wolfe RR. Amino acid control of muscle protein turnover in renal disease. J Renal Nutr. 2005;15:3438.

34. Phillips SM, Tipton KD, Aarsland A, et al. Mixed muscle protein synthesis and breakdown after resistance exercise in humans. Am J Physiol. 1997;273:E99-E107.

35. Deger SM, Hung AM, Gamboa JL, et al. Systemic inflammation is associated with exaggerated skeletal muscle protein catabolism in maintenance hemodialysis patients. $\mathrm{JCl}$ Insight. 2017;2.

36. Cuppari L, de Carvalho AB, Avesani CM, et al. Increased resting energy expenditure in hemodialysis patients with severe hyperparathyroidism. J Am Soc Nephrol. 2004;15: 2933-2939.

37. Bruckert E, Hayem G, Dejager S, et al. Mild to moderate muscular symptoms with high-dosage statin therapy in hyperlipidemic patients-the PRIMO study. Cardiovasc Drugs Ther. 2005;19:403-414.

38. Pennings B, Groen B, de Lange A, et al. Amino acid absorption and subsequent muscle protein accretion following graded intakes of whey protein in elderly men. Am J Physiol Endocrinol Metab. 2012;302:E992-E999.

39. Pennings B, Boirie Y, Senden J, et al. Whey protein stimulates postprandial muscle protein accretion more effectively than do casein and casein hydrolysate in older men. Am J Clin Nutr. 2011;93:997-1005.

40. Strid H, Simren M, Stotzer PO, et al. Patients with chronic renal failure have abnormal small intestinal motility and a high prevalence of small intestinal bacterial overgrowth. Digestion. 2003;67:129-137.

41. Stadlbauer V, Horvath A, Ribitsch W, et al. Structural and functional differences in gut microbiome composition in patients undergoing haemodialysis or peritoneal dialysis. Sci Rep. 2017;7:15601.

42. Shi $\mathrm{K}$, Wang $\mathrm{F}$, Jiang $\mathrm{H}$, et al. Gut bacterial translocation may aggravate microinflammation in hemodialysis patients. Dig Dis Sci. 2014;59:2109-2117.

43. Strid $H$, Simrén $M$, Johansson $A C$, et al. The prevalence of gastrointestinal symptoms in patients with chronic renal failure is increased and associated with impaired psychological general well-being. Nephrol Dial Transplant. 2002;17: 1434-1439.

44. Muto S, Murayama N, Asano Y, et al. Hypergastrinemia and achlorhydria in chronic renal failure. Nephron. 1985;40:143148.

45. Boirie Y, Gachon P, Beaufrere B. Splanchnic and whole-body leucine kinetics in young and elderly men. Am J Clin Nutr. 1997;65:489-495.

46. Jourdan M, Deutz NEP, Cynober L, et al. Features, causes and consequences of splanchnic sequestration of amino acid in old rats. PloS One. 2011;6:e27002.

47. Hodson $\mathrm{N}$, Brown $\mathrm{T}$, Joanisse $\mathrm{S}$, et al. Characterisation of $\mathrm{L}$ type amino acid transporter 1 (LAT1) expression in human skeletal muscle by immunofluorescent microscopy. Nutrients. 2017;10.

48. Drummond MJ, Glynn EL, Fry CS, et al. An increase in essential amino acid availability upregulates amino acid transporter expression in human skeletal muscle. Am J Physiol Endocrinol Metab. 2010;298:E1011-E1018.

49. Divino Filho JC, Barany $P$, Stehle $P$, et al. Free amino-acid levels simultaneously collected in plasma, muscle, and erythrocytes of uraemic patients. Nephrol Dial Transplant. 1997;12:2339-2348.

50. Fujita S, Dreyer HC, Drummond MJ, et al. Nutrient signalling in the regulation of human muscle protein synthesis. J Physiol. 2007;582:813-823.

51. Rasmussen BB, Fujita S, Wolfe RR, et al. Insulin resistance of muscle protein metabolism in aging. FASEB J. 2006;20: 768-769.

52. Moore DR, Lysecki $P$, Breen L, et al. Chronic alterations in blood pH affect fasting-state amino acid oxidation and myofibrillar and albumin protein synthesis in healthy young men [abstract]. FASEB J. 2017;31(suppl 1):1014-1015. Abstract 1036.14.

53. Centor R. Serum total carbon dioxide. In: Walker H, Hall W, Hurst J, eds. Clinical Methods: The History, Physical, and Laboratory Examinations. 3rd ed. Boston: Butterworths; 1990:888-889. 